\title{
Nanosized-hybrid colloids of poly(acrylic acid)/titania prepared via in situ sol-gel reaction
}

\author{
Hung-Jen Chen ${ }^{\mathrm{a}}$, Pei-Chi Jian ${ }^{\mathrm{b}}$, Jui-Hung Chen ${ }^{\mathrm{b}}$, Leeyih Wang ${ }^{\mathrm{b}, \mathrm{c}}$, Wen-Yen Chiu ${ }^{\mathrm{a}, \mathrm{b}, *}$ \\ ${ }^{a}$ Department of Chemical Engineering, National Taiwan University, Taipei, Taiwan, ROC \\ ${ }^{\mathrm{b}}$ Institute of Polymer Science and Engineering, National Taiwan University, Taipei, Taiwan, ROC \\ ${ }^{\mathrm{c}}$ Center for Condensed Matter Sciences, National Taiwan University, Taipei, Taiwan, ROC
}

Received 17 October 2005; received in revised form 1 November 2005; accepted 13 December 2005

Available online 6 March 2006

\begin{abstract}
Nanosize-hybrid colloids of poly(acrylic acid) (PAA)-titania $\left(\mathrm{TiO}_{2}\right)$ were synthesized and characterized. The methods of preparation were based on an in situ sol-gel technique using titanium isopropoxide as precursor in the butanol solution of PAA. Two synthetic pathways to the fabrication of hybrids were utilized, involving adding titanium precursor after or before the PAA was fully dissolved. Different phenomena of phase separation and gelation were observed in these two synthetic pathways, but both yielded stable colloidal solutions after further heating. Various mole ratios of PAA/ titanium isopropoxide/water and synthetic routes were employed to examine the interaction between PAA and titania. The hybrid materials were characterized by Fourier transform infrared spectroscopy (FTIR), thermogravimetric analysis (TGA), differential scanning calorimetry (DSC) and scanning electronic microscopy (SEM). The FTIR results verified the successful formation of the chelation bond between PAA and titania. TGA demonstrated that the thermal stability of pure PAA was improved by chelating with titania. DSC showed the PAA strongly interacted with titania, leading to the confinement of the thermal motion of PAA chains. The SEM results revealed that the preparation method and the mole ratios of PAA/ titanium precursor/water considerably affected the size and shape of PAA-titania hybrid aggregates, and the extent of aggregation.

(C) 2006 Elsevier Ltd and Techna Group S.r.l. All rights reserved.
\end{abstract}

Keywords: Poly(acrylic acid)-titania; Hybrid colloid; Chelation; In situ sol-gel reaction

\section{Introduction}

In a successful organic/inorganic hybrid, the inorganic particles can eliminate the disadvantages of organic materials, as the advantages of organic and inorganic materials are combined, broadening their application. Moreover, most of the interest in such hybrid materials basically derives from the virtue of combining the novel multi-functional advanced organic/inorganic materials in a single material on the nanoscale. However, the inherent difference between organic and inorganic materials in both physical and chemical properties frequently causes the serious phase separation in a simple blending system. Three major preparation methods have been successfully developed to overcome these problems.

\footnotetext{
* Corresponding author at: No. 1, Sec. 4, Roosevelt Road, Taipei, Taiwan 106, ROC. Tel.: +886 2 23623259; fax: +886 223623259 .

E-mail address: ycchiu@ntu.edu.tw (W.-Y. Chiu).
}

Earlier, the main techniques for fabricating a good organic/ inorganic hybrid used to involve finding a suitable co-solvent for each of the constituents [1,2] or modifying the surface structure of inorganic particles to disperse them effectively in organic solvent [3-7]. For example, in organic solar cell, lower vapor pressure such as xylene and chlorobenzene improved the mixing of poly(3-hexylthiophene) (P3HT) and titania to an extent that exceeded that of THF and chloroform and enhanced the photovoltaic cell efficiency one to two orders of magnitude to $0.42 \%$ in Air Mass (A.M.) 1.0 [1]. Chlorobenzene dispersed $[6,6]$-phenyl C61 butyric acid methyl ester (PCBM) $\left(\mathrm{C}_{60}\right.$ derivative) in (poly)[2-methyl,5-(3*,7** dimethyl-octyloxy)]$p$-phenylene vinylene (MDMO-PPV) better than toluene and increased the efficiency from 0.9 to $2.5 \%$ under light illumination through A.M. 1.5 [2]. Colvin et al. [3] synthesized nanocrystalline titania in nonhydrolytic solution, providing nanocrystals without a surface hydroxyl group, which were highly dispersible in organic solvent. Binding an organic compound to the surface hydroxyl group of titania was another approach to synthesizing nanocrystalline titania [4-7]. 
Secondly, binding inorganic particles to organic molecules using a bi-functional coupling agent was the most direct method. The nano-inorganic particles generally aggregate easily because they have high surface energy. The coupling agent could link the organic and the inorganic phases by covalent bonding, hydrogen bonding or simple physical interactions that prevented phase separation [8-16]. Consider, for example, the organic solar cell; if the donor materials (organic) and the acceptor materials (inorganic) can bind together, the phase separation was reduced to the nano-scale. The overall efficiency would be enhanced because it created the largest reactive surface for the splitting of excitons; the holes and electrons would thus be efficiently transported in the bicontinuous phase [8-10]. In optics, the film thickness, the refractive index and optical transparency could be controlled by the amount of titania and the species of coupling agent used [11-14]. Incorporating titania into advanced engineering polymers improved the overall mechanical properties [15]. In self-assembled monolayer techniques, organic molecules grown on a titania surface using different functional silanes determined the surface properties [16].

The third method was the in situ sol-gel reaction of inorganic precursors in the solution of organic species. The in situ sol-gel reaction of titania in various polymer solutions was most likely to disperse the titania nanoparticles effectively in polymer solutions if the nanoparticles strongly interacted with the polymer chains, enhancing the electro-optical, mechanical, thermal and coating properties of the resulting composites [1719]. Hybrids of polyimide/ $\mathrm{TiO}_{2}$ with improved quality, such as high thermal stability, high optical transparency, and good mechanical properties, were fabricated by the in situ sol-gel reaction of poly(amic acid) precursor and modified titanium precursor [20-21]. Furthermore, using the titanium precursor molecules adsorbed on a polymer chain yielded a wide range of porosities, architectures and surface areas of titania films, which could be synthesized using a range of polymer gels as templates [22-24].

For comparing the preparation of organic/ $\mathrm{SiO}_{2}$ with organic/ $\mathrm{TiO}_{2}$ hybrids via the in situ sol-gel reaction method, the particle size and dispersion ability of silica were controlled relatively easily by changing the reaction conditions because the hydrolysis and condensation reactions of silicon alkoxides was slower than those of titanium alkoxides [25]. Therefore, acetic acid has been used as a chelating agent to inhibit the hydrolysis of titanium alkoxide precursors during $\mathrm{TiO}_{2}$ formation because carboxylic acid could act as a ligand and bond directly to the titanium, by both chelating and bridging [26-27]. Accordingly, the sol-gel reaction of titanium alkoxide in a carboxylic acid-containing polymer solution enabled the simpler and more efficient fabrication of a polymer/titania hybrid [10,27-30]. PAA performed chelating and sterically hindering roles, and so was chosen herein to synthesize the organic/titania hybrid. The effects of the mole ratios of PAA/ titanium precursor/water as well as the order in which the reactants were added, on the interaction between PAA and titania, the degree of aggregation, the particle size and the particle shape were studied in this work.

\section{Experimental}

\subsection{Materials and preparations}

Poly(acrylic acid) (PAA) (Aldrich, $M_{\mathrm{w}}=2000$ ), titaniu$\mathrm{m}(\mathrm{IV}$ ) isopropoxide (TIP) (Acros, 98\%) and 1-butanol (Acros, 99.5\%) were used as received. The water used in the sol-gel reaction was purified using a Millipore Milli-Q system.

Table 1 presents the reagents and their mole ratios used in the preparation reaction of PAA-titania hybrids. For the convenience of comparison, $1 \mathrm{~mol}$ of PAA containing $27 \mathrm{~mol}$ of carboxylic acid groups was assumed. The following notation was used; II-T1-P5-W1, in which the first term refers to the preparation method empolyed; the second, third, and fourth terms ( $\mathrm{T}, \mathrm{P}$, and $\mathrm{W}$ ) represent the titanium isopropoxide, PAA, and water, respectively, and the number increases with the increase of content. Two examples are presented to reveal the real amount of reagents used in the reaction.

\subsubsection{Method I}

With respect to I-T1-P5, $2.5 \mathrm{~g}$ of PAA was firstly fully dissolved in $20 \mathrm{ml}$ of butanol and water was generated by partial esterification of free carboxylic acid and butanol. Another solution of $2 \mathrm{ml}$ of TIP and $5 \mathrm{ml}$ of butanol was added dropwise to the PAA solution, and mixed using a magnetically driven stirrer. The solution was stirred vigorously to avoid local aggregation and reacted at $90{ }^{\circ} \mathrm{C}$ for $10 \mathrm{~h}$. Fig. 1 presents the synthetic route. The amounts of PAA and TIP were changed to elucidate their influence on the properties of the PAA/titania hybrid materials.

\subsubsection{Method II}

Large portions of the synthetic route were similar to method I. The main difference was the order of dissolution and the effect of adding water. For II-T1-P5-W0, $2 \mathrm{ml}$ of TIP was initially dissolved in $25 \mathrm{ml}$ of butanol. Subsequently, $2.5 \mathrm{~g}$ of PAA was added to the TIP solution and stirred for $30 \mathrm{~min}$. Then, the solution was heated to $90{ }^{\circ} \mathrm{C}$, maintained at that temperature

\begin{tabular}{|c|c|c|c|c|}
\hline Sample & $\begin{array}{l}\text { TIP } \\
(\mathrm{mol})\end{array}$ & $\begin{array}{l}\mathrm{COOH} \\
(\mathrm{mol})\end{array}$ & $\begin{array}{l}\mathrm{H}_{2} \mathrm{O} \\
(\mathrm{mol})\end{array}$ & $\begin{array}{l}\text { Butanol } \\
(\mathrm{mol})\end{array}$ \\
\hline I-T1-P1 & 1 & 3.02 & 0 & 40.4 \\
\hline I-T1-P2 & 1 & 3.63 & 0 & 40.4 \\
\hline I-T1-P3 & 1 & 4.03 & 0 & 40.4 \\
\hline I-T1-P4 & 1 & 4.43 & 0 & 40.4 \\
\hline I-T1-P5 & 1 & 5.04 & 0 & 40.4 \\
\hline I-T1-P6 & 1 & 6.04 & 0 & 40.4 \\
\hline I-T1-P5 & 1 & 5.04 & 0 & 40.4 \\
\hline I-T2-P5 & 1.25 & 5.04 & 0 & 40.4 \\
\hline I-T3-P5 & 1.5 & 5.04 & 0 & 40.4 \\
\hline II-T1-P5-W0 & 1 & 5.04 & 0 & 40.4 \\
\hline II-T1-P5-W1 & 1 & 5.04 & 2.98 & 40.4 \\
\hline II-T1-P5-W2 & 1 & 5.04 & 8.26 & 40.4 \\
\hline II-T(0.75)-P5-W0 & 0.75 & 5.04 & 0 & 40.4 \\
\hline
\end{tabular}

The moles of all components are normalized. 

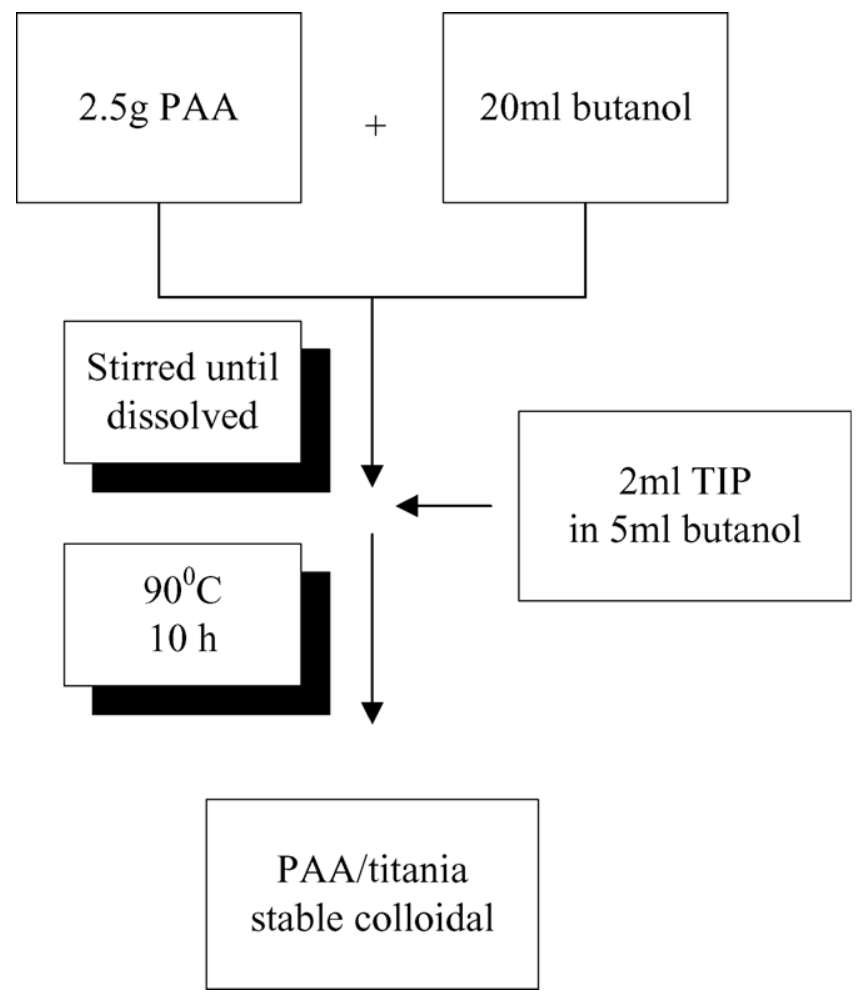

Fig. 1. The synthetic route of method I.

for $10 \mathrm{~h}$. In this method, the water was gradually released from partial esterification and the sol-gel reaction proceeded at a slower rate. When the effect of the adding water in the reaction was studied, $2 \mathrm{ml}$ of TIP was initially dissolved in $20 \mathrm{ml}$, instead of $25 \mathrm{ml}$, of butanol. Then, an additional solution of $5 \mathrm{ml}$ of butanol and a desired amount of water were added dropwise. The synthetic route of method II was displayed in Fig. 2.

\subsection{Measurements}

The Fourier transform infrared (FTIR) absorption spectra were recorded between 4000 and $400 \mathrm{~cm}^{-1}$ using a Bio-Rad (FTS-3000). A thermogravimetric analyzer (TGA) from Perkin Elmer (TGA-7) was used to explore the thermal degradation of PAA/titania hybrid at a heating rate of $10{ }^{\circ} \mathrm{C} / \mathrm{min}$. The glass transition temperature of the hybrids was measured by differential scanning calorimetry (DSC) using a TA (DSC2010), at a heating rate and a nitrogen flow rate of $10^{\circ} \mathrm{C} / \mathrm{min}$ and $50 \mathrm{~mL} / \mathrm{min}$, respectively. The size of the particles and the dispersion were investigated using a Hitachi (S-800) Scanning Electronic Microscope (SEM).

\section{Results and discussion}

\subsection{Phase separation}

In the system studied here, the reactive process might lead to gelation as well as phase separation. The phase separation in PMMA/silica sol-gel systems was well described by Silveira et al. [31]. In which, the phase morphology of the hybrid

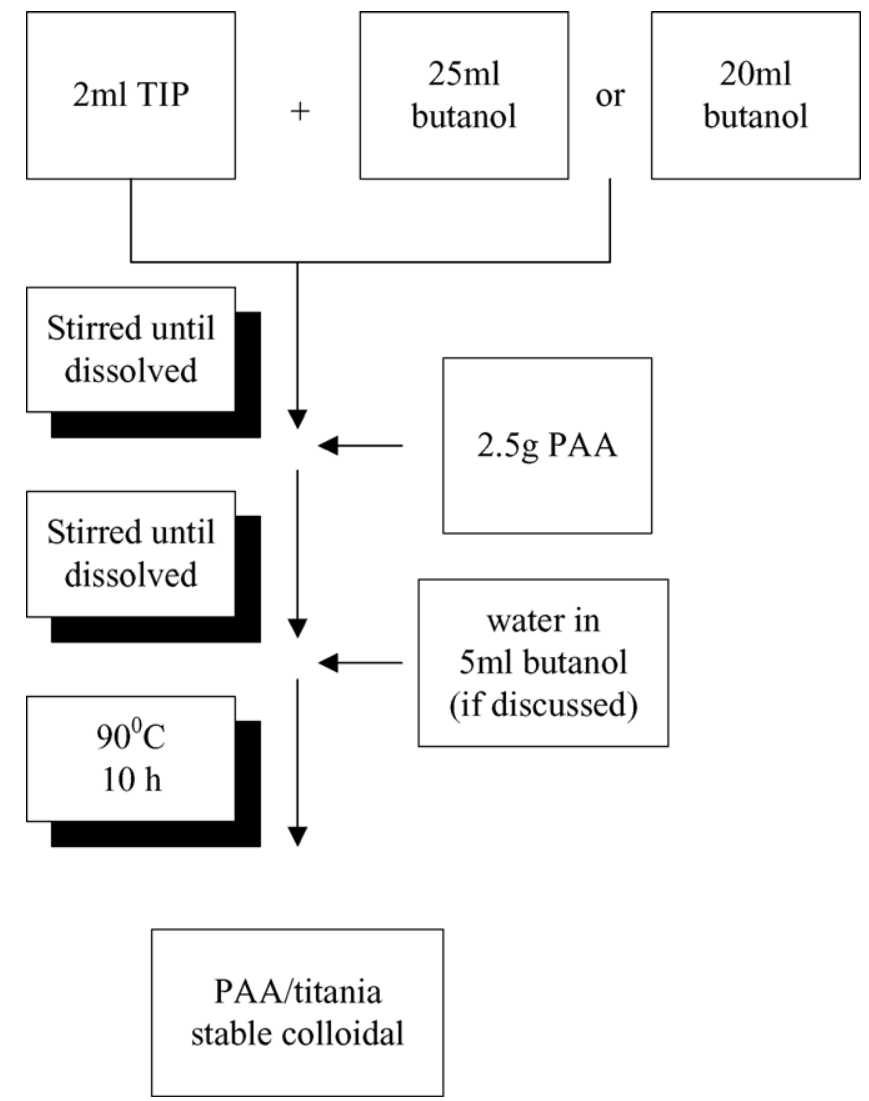

Fig. 2. The synthetic route of method II.

material was governed by the composition of compounds, the reactive process and the solvent evaporation. In the system herein, the phase morphology of the hybrid colloid was determined by the composition of the compounds and the reactive process but no solvent evaporation was considered because the reaction proceeded in a closed system. Fig. 3(a) and (b) show the phase diagrams, involving phase separation and gelation during the sol-gel process, of the colloid systems prepared by methods I and II, respectively. $\Phi$ is the mer concentration in the dilute medium. Analogous to a phase separation process occurring by temperature variation, phase separation induced by chemical reaction at constant temperature may be described by a phase diagram in which the progress of the reaction is represented by an equivalent temperature, $T_{\mathrm{eq}}$, as the temperature influences the phase separation process [31]. Before the reaction begins, the reaction mixture is in the singlephase region, so $T_{\text {eq }}$ is infinite. $T_{\text {eq }}$ decreases from infinity to a low value as the chemical reaction proceeds. As $T_{\text {eq }}$ decreases, the reaction system may enter the two-phase or the gelation region, depending on the composition.

In method I, phase separation and gelation occurred simultaneously when the titanium precursor was added to the polymer solution, within the range of the compositions of our experiments, as described in Fig. 3(a). For qualitative description, the A line, as an example, was to contact the phase separation and gelation curves almost simultaneously, so the gel contained titania aggregates formed firstly. However, method II yielded a different observation: after the PAA was fully 


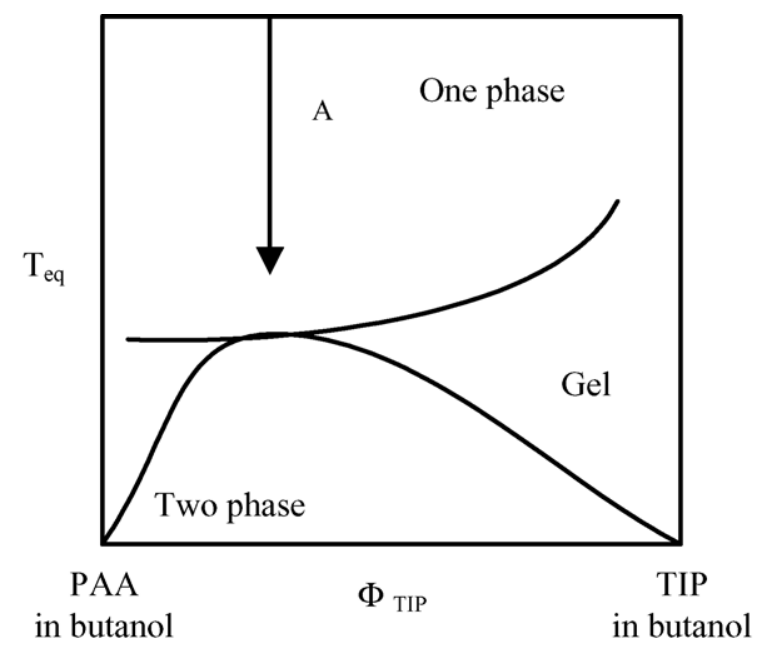

(a)

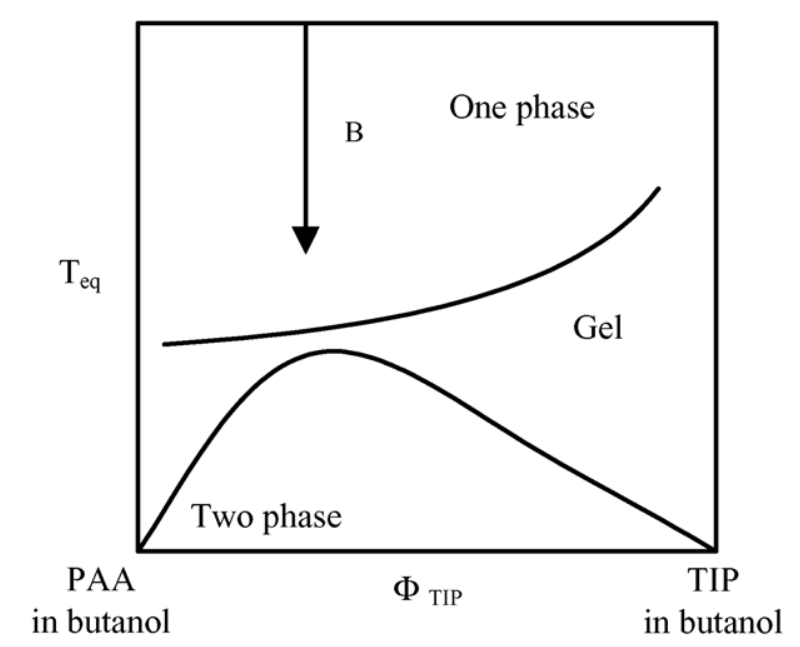

(b)

Fig. 3. (a) The qualitative representation of phase diagram during the sol-gel process of method I. (b) The qualitative representation of phase diagram during the sol-gel process of method II.

dissolved, the gelation was observed firstly, as shown in Fig. 3(b). The B line, as an example, crossed the gelation curve first than phase separation curve.

\subsubsection{Method I}

The relative position of the phase separation and the gelation curves caused the apparent phase transformation and was determined by whether the particle nucleation and growth proceeded easily. As determined experimentally, the water generated by partially esterification in method I promoted the nucleation and growth of particles, so the phase separation curve was near the gelation curve and the reaction system exhibited the co-occurrence of phase separation and gelation.

\subsubsection{Method II}

The phenomenon of gelation was believed to be related to the formation of hybrid networks between PAA and TIP due to the chelation reaction. The titanium precursor was present in the solution. The growth of titania was slow because water was released gradually from the partial esterification reaction of PAA and butanol. Therefore, the phase separation curve became lower than the gelation curve. Gelation was observed firstly.

At room temperature, the gel contained titania aggregates formed in method I. The aggregation of particles was due to the hydrogen bonds. The solution was then heated at high temperature to promote the chelating reaction between the carboxylic acid group of PAA and titania. The gel contained titania aggregates from the solution changed to nanosized stable colloid after a reaction was carried out at $90{ }^{\circ} \mathrm{C}$ for $10 \mathrm{~h}$. It could be due to the fact that the hydrogen bond interaction between the aggregated particles was destroyed and separated nanoparticles were formed in the solution at high temperature. Then, most of the PAA chains, including the free PAA chains in solution, were bound to the separated nanoparticles via chelating bonds because numerous new surfaces were created from the separated nanoparticles. As for method II, this heating process was to promote the water production from partially esterification of PAA and butanol, and then accelerated the solgel reaction of TIP. Interestingly, whether in method I or method II, the stable colloid state was maintained from $90{ }^{\circ} \mathrm{C}$ to room temperature, because the chelated PAA chains on the titania surface exhibited steric hindrance between the particles, resulting in the difficult aggregation among particles. The effect of chelated PAA chains thus enabled the nanosized PAA-titania hybrid to be synthesized.

\subsection{FTIR analysis}

Figs. 4 and 5 show the FTIR spectra of pure PAA and the PAA-titania hybrid materials prepared by method I. Fig. 4 presents the FTIR spectra of hybrid materials prepared using different amounts of PAA. Table 2 lists the peak assignments [26,30,32-34]. The broad band at around $3400 \mathrm{~cm}^{-1}$ was assigned to stretching vibrations of $\mathrm{Ti}-\mathrm{OH}$ group. It exhibited sharp bands at $2873-2960 \mathrm{~cm}^{-1}$, corresponding to the stretching vibrations of the aliphatic $\mathrm{CH}_{2}$ and $\mathrm{CH}_{3}$ groups [27]. The bands in the region $1037-1122 \mathrm{~cm}^{-1}$ corresponded to OR groups linked to titanium.

The characteristic absorption band of carbonyl $(\mathrm{C}=\mathrm{O})$ of pure PAA was around $1699-1742 \mathrm{~cm}^{-1}$, it was overlapped by the vibration of free state and self-associated dimmer by hydrogen bonding [33]. The carboxylic acid groups of pure PAA showed three different functions. First, part of carboxylic acid groups proceeded esterification for the generation of water. Second, some of carboxylic acid groups chelated with TIP. When the PAA reacted with TIP, new bands from 1419 to $1560 \mathrm{~cm}^{-1}$ were observed. It was used to identify the carboxylic acid groups that had been chelated with titania, indicating that the titania have successfully chelated with PAA chains [26]. According to the literature, $\mathrm{COOH}$ acted as a bidentate ligand-a chelating ligand at 1521 and $1458 \mathrm{~cm}^{-1}$ (bound to one Ti) — and a bridging ligand at 1560 and $1419 \mathrm{~cm}^{-1}$ (bound to two Ti) and a monodentate ligand at $1276 \mathrm{~cm}^{-1}$. In the following, a chelating ligand, a bridging 


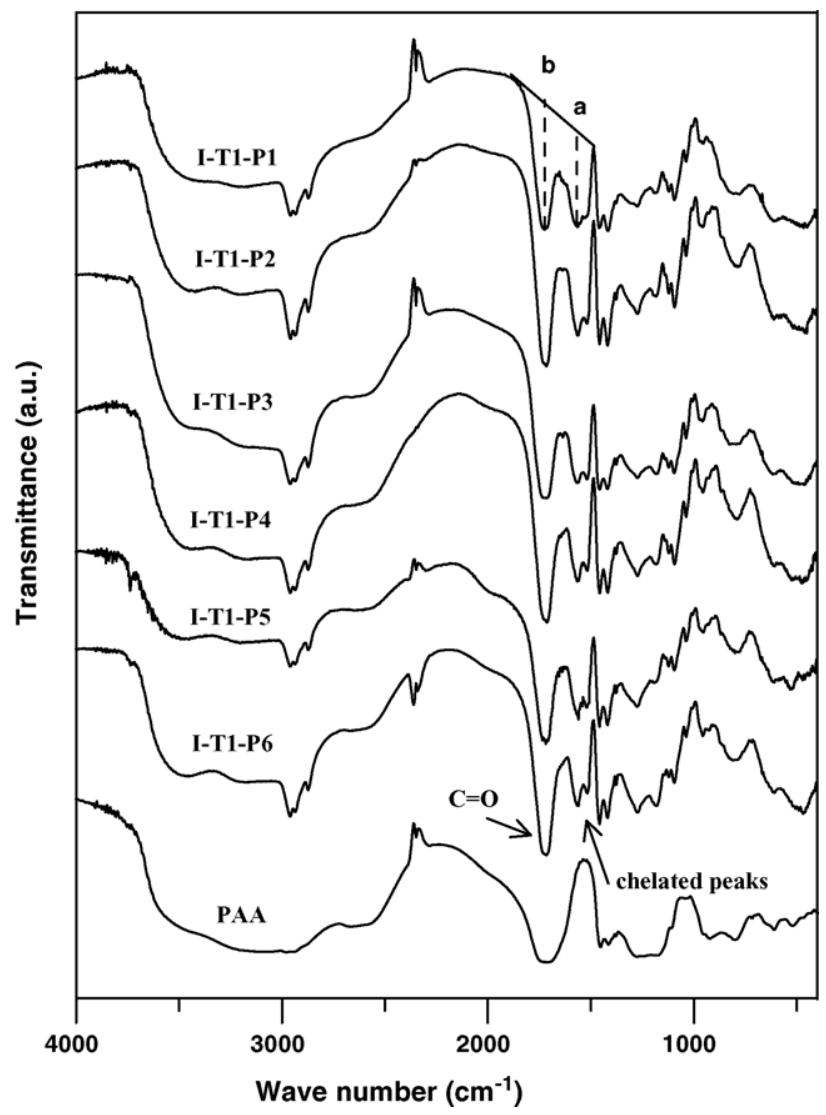

Fig. 4. FTIR spectra of PAA and the hybrids prepared by method I. The content of PAA increases from sample I-T1-P1 to I-T1-P6.

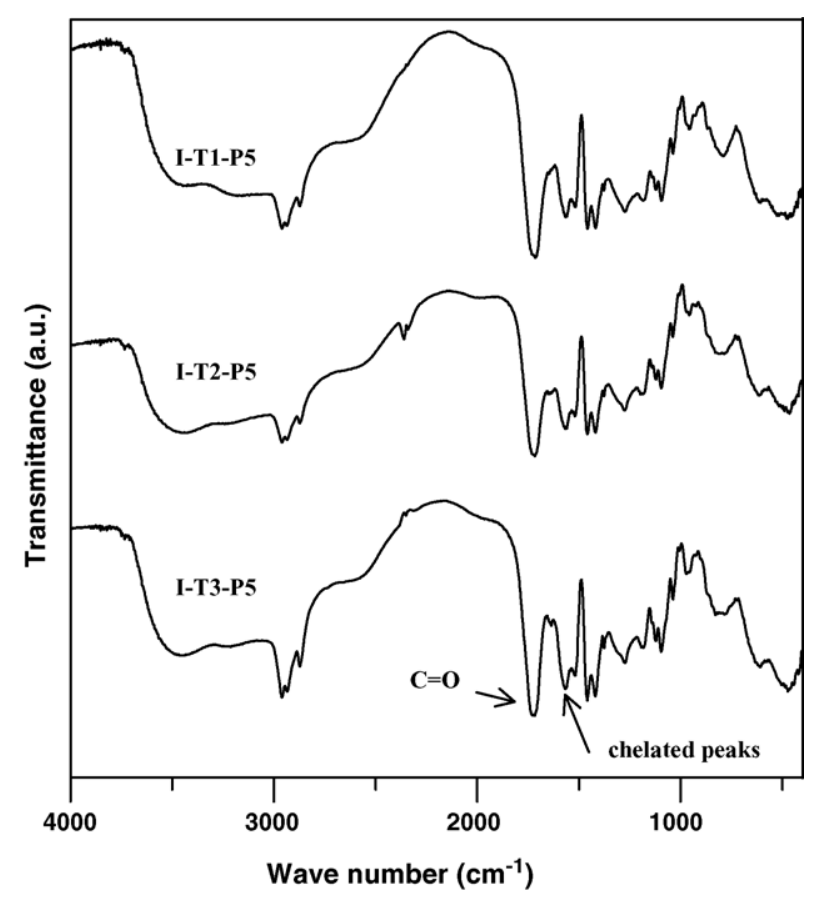

Fig. 5. FTIR spectra of the hybrids prepared by method I. The content of TIP increases from sample I-T1-P5 to I-T3-P5.
Table 2

FTIR observed frequencies and assignments for the prepared hybrids

\begin{tabular}{ll}
\hline $3400 \mathrm{~cm}^{-1}$, broad & $\mathrm{O}-\mathrm{H}$ stretching \\
$2960-2873 \mathrm{~cm}^{-1}$ & $\mathrm{CH}_{2}$ or $\mathrm{CH}_{3}$ stretching \\
$1718 \mathrm{~cm}^{-1}$, strong & $\mathrm{C}=\mathrm{O}$ (hydrogen bond interaction between free \\
& COOH and COOR) \\
$1560 \mathrm{~cm}^{-1}$ & COO antisymmetric stretching, bidentate bridging \\
$1521 \mathrm{~cm}^{-1}$ & COO antisymmetric stretching, bidentate chelating \\
$1458 \mathrm{~cm}^{-1}$ & COO symmetric stretching, bidentate chelating \\
& or CH deformating of PAA \\
$1419 \mathrm{~cm}^{-1}$ & COO symmetric stretching, bidentate bridging \\
& or C-O stretching coupled with O-H in-plane \\
bending of PAA & COO symmetric stretching, monodentate \\
$1276 \mathrm{~cm}^{-1}$ & C-O stretching coupled with O-H in plane bending \\
$1184 \mathrm{~cm}^{-1}$ & Ti-O-C vibrations \\
$1122-1037 \mathrm{~cm}^{-1}$ &
\end{tabular}

$[26,30,32-34]$.

ligand and a monodentate ligand were all considered to have chelating bonds. Finally, the remained carboxylic acid groups were free.

A carbonyl vibration was observed at $1718 \mathrm{~cm}^{-1}$ for all PAA-titania hybrids. From the literature, the free carbonyl vibration of poly methyl methacrylate (PMMA) was at $1730 \mathrm{~cm}^{-1}$, whereas, this carbonyl vibration would shift to $1705 \mathrm{~cm}^{-1}$ when it had hydrogen bond with free carboxylic acid group of poly methacrylic acid (PMAA) [34]. It meant that the carbonyl vibration of ester group would shift from $1730 \mathrm{~cm}^{-1}$ to lower wave number as it had hydrogen bond with carboxylic acid group. It accounted for the co-existence of ester group and carboxylic acid group in our system.

The FTIR spectra and Table 2 reveal that when PAA was chelated with titania, new bands at 1560 and $1521 \mathrm{~cm}^{-1}$ were observed. The ratio of the intensity of the chelating bond $\left(1560 \mathrm{~cm}^{-1}\right)$ to that of the $\mathrm{C}=\mathrm{O}$ bond $\left(1718 \mathrm{~cm}^{-1}\right)$ was used to roughly estimate the ratio of the amount of chelated $\mathrm{COOH}$ to the amount of unchelated $\mathrm{COOH}$, yielding the chelating efficiency. It was mentioned again that the unchelated $\mathrm{COOH}$ included free $\mathrm{COOH}$ and $\mathrm{COOR}$ formed from esterification. Fig. 4 depicts the gradual drop in chelating efficiency as the PAA content increases, where the chelating efficiency was calculated based on the following equation:

chelating efficiency $=\frac{a}{a+b} \times 100 \%$.

In Eq. (1), $a$ and $b$ were labeled in Fig. 4 and represented the amount of chelated $\mathrm{COOH}$ and the amount of unchelated $\mathrm{COOH}$, respectively.

Fig. 5 shows the FTIR spectra of hybrid materials prepared using various amounts of TIP by method I. The chelating efficiency decreased as the amount of TIP decreased. Combining Figs. 4 and 5 indicated that the ratio of PAA to TIP affected the chelating efficiency. This result was predicted. The chelating efficiency dropped as the ratio of PAA to TIP increased, because the amount of excess PAA increased. In relation to method II, comparing II-T1-P5-W0 with II-T(0.75)P5-W0 revealed that, as the amount of TIP is reduced, the ratio of PAA to TIP increased, so the chelating efficiency was 


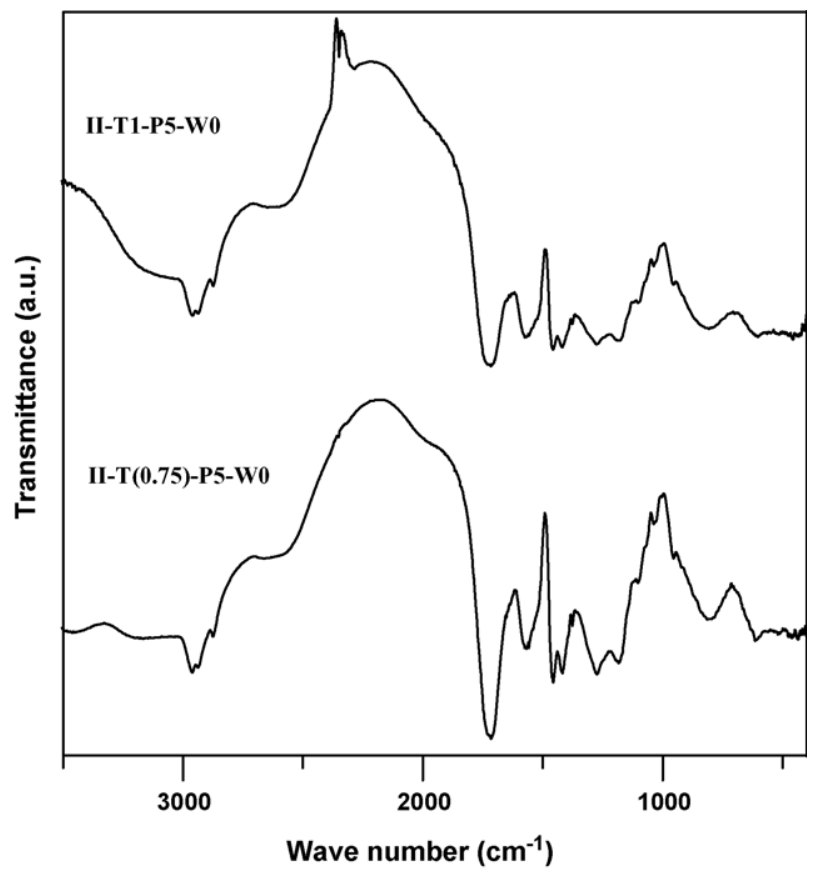

Fig. 6. FTIR spectra of the hybrids prepared by method II.

reduced, as shown in Fig. 6. The chelating efficiencies of all hybrids were shown in Fig. 7.

\subsection{TGA analysis}

Thermal information on the prepared hybrids was obtained from TGA analysis. Figs. 8-10 plot TGA curves of PAA-titania hybrids with various mole ratios of PAA to TIP to water, prepared by methods I and II, respectively. Table 3 presents the state and the residual weight of the hybrids at $800{ }^{\circ} \mathrm{C}$ from TGA analysis. Table 3 also gives the theoretical residual weights of

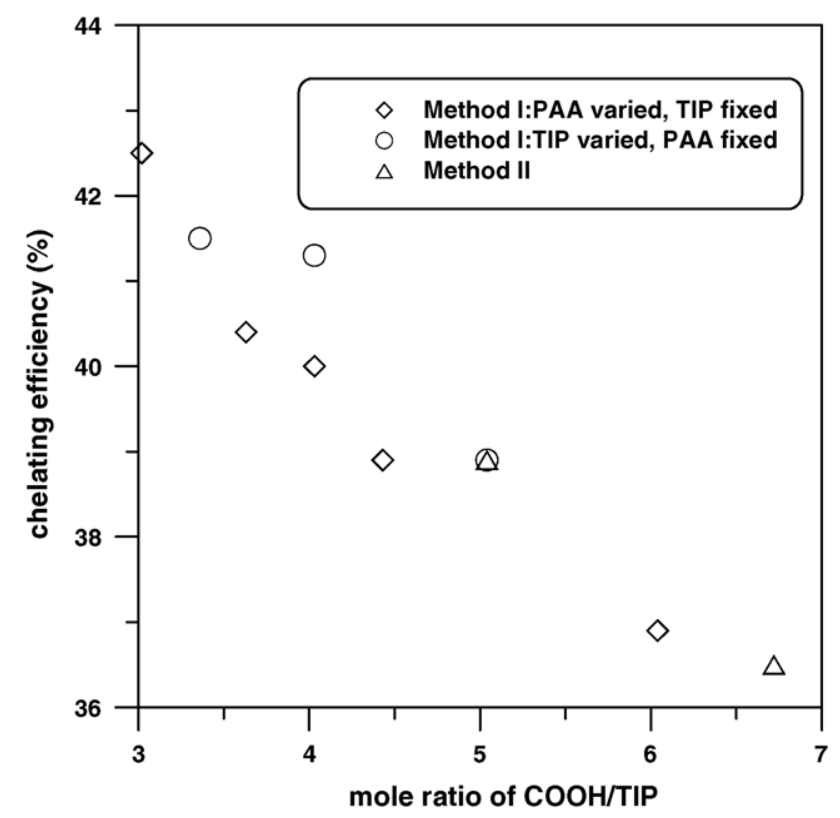

Fig. 7. The chelating efficiency vs. mole ratio of $\mathrm{COOH} / \mathrm{TIP}$.

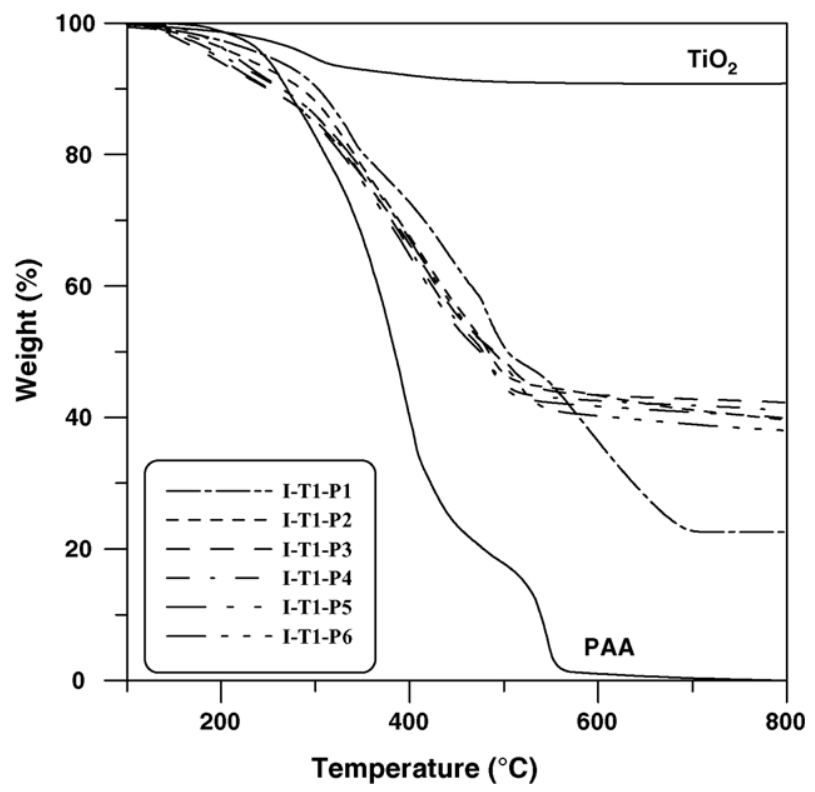

Fig. 8. TGA curves of PAA, $\mathrm{TiO}_{2}$ and the hybrids prepared by method I. The content of PAA increases from sample I-T1-P1 to I-T1-P6.

the hybrids at $800{ }^{\circ} \mathrm{C}$, which is calculated by assuming that all of the PAA are decomposed and that the efficiency of transformation of the titanium precursor to titania is $100 \%$, as represented in the following:

theoretical residual (TR\%)

$$
=\frac{(\text { weight of TIP }) \times M_{\mathrm{TiO}_{2}} / M_{\mathrm{TIP}}}{(\text { weight of PAA })+(\text { weight of TIP }) \times M_{\mathrm{TiO}_{2}} / M_{\mathrm{TIP}}}
$$

where $M_{\mathrm{TiO}_{2}}$ and $M_{\mathrm{TIP}}$ are the molecular weight of $\mathrm{TiO}_{2}$ and TIP, respectively. The interaction between PAA and titania was strong or weak, as determined by whether the hybrid was black or white at $800{ }^{\circ} \mathrm{C} . T_{\mathrm{d}}$ also elucidated the effect of titania on the

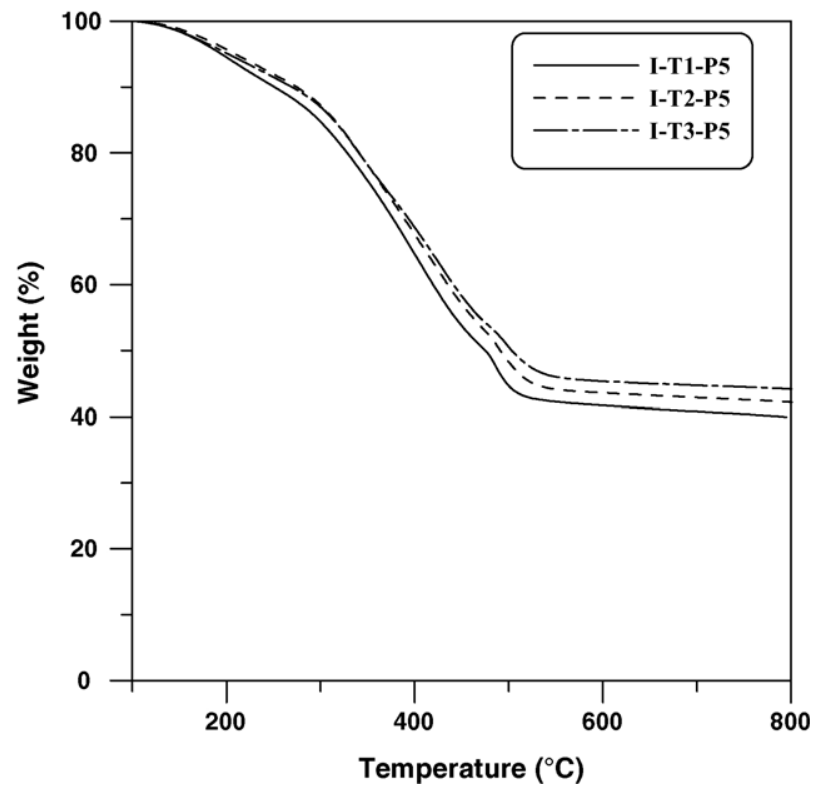

Fig. 9. TGA curves of the hybrids prepared by method I. The content of TIP increases from sample I-T1-P5 to I-T3-P5. 


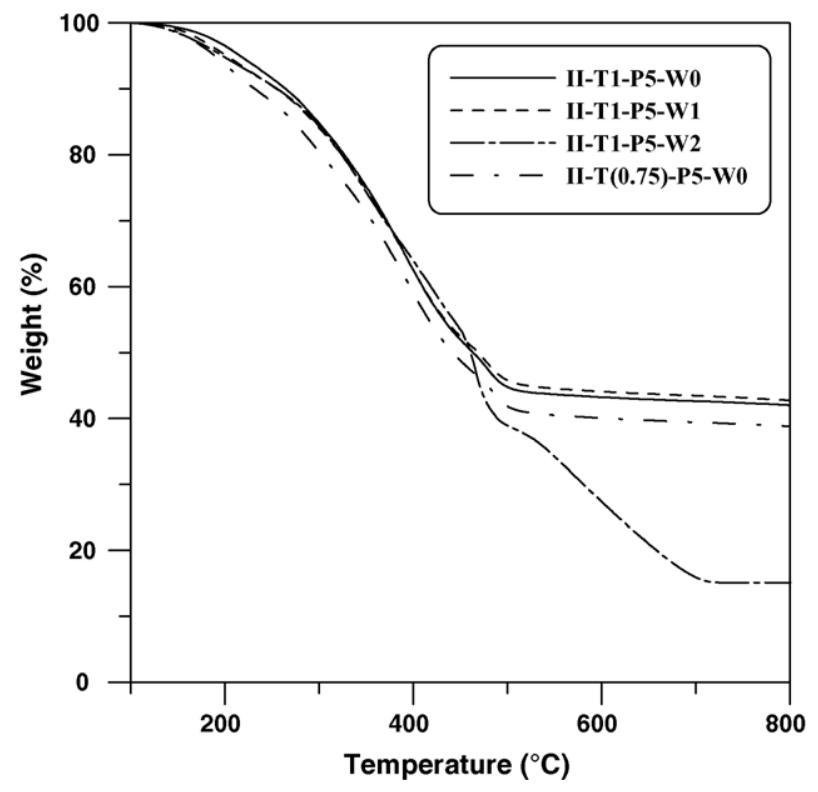

Fig. 10. TGA curves of the hybrids prepared by method II.

thermal behavior of pure PAA. In addition, the degree of chelation of PAA with titania $(D)$ was assumed roughly proportional to the difference ( $\Delta$ value) between experimental and theoretical residual, and the $\Delta$ values were listed in Table 3 . Here, the larger or smaller $\Delta$ value was in accordance with the higher or lower degree of chelation.

\subsubsection{Method I}

Fig. 8 plots the effect of the amount of PAA on the thermal properties of the hybrids. Table 3 shows that hybrids at $800{ }^{\circ} \mathrm{C}$ change from white to grey to black, and that the $\Delta$ values vary from 17.12 to $23.11 \%$ as the amount of PAA increases. It was believed that the black residue was formed by the strong interaction between PAA chains and titania. The $\Delta$ value increased with the increase of PAA content because the amount of chelated PAA increased with increasing the PAA content. As for I-T1-P1, the use of less PAA weakened the interaction between PAA and titania, so PAA was easily burnt out from the titania surface and the yielded product was white. Of course, the experimental amount of the residue was lower than the theoretical value because the latter was calculated based on the assumption that the efficiency of transformation of the titanium precursor to titania was $100 \%$, which was the maximum value. The thermal decomposition temperature $\left(T_{\mathrm{d}}\right)$ of the prepared hybrid material was lower than that of pure PAA in the first stage between 100 and $250{ }^{\circ} \mathrm{C}$ because of the loss the Ti-OR groups. In the main decomposition stage between 250 and $500{ }^{\circ} \mathrm{C}$, the $T_{\mathrm{d}}$ of the hybrid was increased by the strong interaction between PAA chains and titania. Notably, the compound I-T1-P1 had the highest $T_{\mathrm{d}}$ and pyrolysis temperature, probably because the inorganic part, titania, dominated the thermal properties of the hybrid.

Fig. 9 shows the effect of the amount of TIP on the thermal properties of the hybrids. All hybrids were black at $800{ }^{\circ} \mathrm{C}$ and the $\Delta$ value (the same meaning of degree of chelation) increased with decreasing the amount of TIP. Combining the results in Figs. 8 and 9, it revealed that the $\Delta$ value (or roughly degree of chelation) increased with increasing the ratio of PAA to TIP, as presented in Fig. 11. The $T_{\mathrm{d}}$ of the main decomposition between 250 and $500{ }^{\circ} \mathrm{C}$ increased with increasing the amount of TIP as expected, because the influence of titania on PAA was enhanced.

\subsubsection{Method II}

Fig. 10 shows the TGA curves of the hybrids prepared by method II. Table 3 elucidates the influence of the added water and the ratio of PAA to TIP on the $\Delta$ value (or roughly degree of chelation). The effect of the order in which the reactants were added on the $\Delta$ value (or roughly degree of chelation) was determined by comparing the results in Figs. 8 and 10 with those in Table 3. Comparing the hybrids of II-T1-P5-W0, II-T1P5-W1 and II-T1-P5-W2 demonstrated the effect of adding water on the state of the hybrids at $800{ }^{\circ} \mathrm{C}$ and the $\Delta$ value (or

Table 3

The residual weight and state of the PAA/titania hybrids at $800{ }^{\circ} \mathrm{C}$ from TGA analysis

\begin{tabular}{|c|c|c|c|c|}
\hline Sample & $\begin{array}{l}\text { State at } \\
800^{\circ} \mathrm{C}\end{array}$ & $\begin{array}{l}\text { Experimental Residual } \\
\text { at } 800{ }^{\circ} \mathrm{C}, \mathrm{ER}(\%)\end{array}$ & $\begin{array}{l}\text { Theoretical residual, } \\
\text { TR }(\%)^{\mathrm{a}}\end{array}$ & $\begin{array}{l}\Delta(\mathrm{ER}-\mathrm{TR})(\%) \\
(\text { degree of chelation (a.u.)) }\end{array}$ \\
\hline I-T1-P1 & White & 22.55 & 25.92 & $\mathrm{~b}$ \\
\hline I-T1-P2 & Grey & 39.7 & 22.58 & 17.12 \\
\hline I-T1-P3 & Black & 42.26 & 20.79 & 21.47 \\
\hline I-T1-P4 & Black & 41.1 & 19.26 & 21.84 \\
\hline I-T1-P5 & Black & 39.9 & 17.35 & 22.55 \\
\hline I-T1-P6 & Black & 38 & 14.89 & 23.11 \\
\hline I-T1-P5 & Black & 39.9 & 17.35 & 22.55 \\
\hline I-T2-P5 & Black & 42.19 & 20.78 & 21.41 \\
\hline I-T3-P5 & Black & 44.15 & 23.98 & 20.17 \\
\hline II-T1-P5-W0 & Black & 42 & 17.35 & 24.65 \\
\hline II-T1-P5-W1 & Black & 42.7 & 17.35 & 25.35 \\
\hline II-T1-P5-W2 & White & 15.13 & 17.35 & $\mathrm{~b}$ \\
\hline II-T(0.75)-P5-W0 & Black & 38.8 & 13.61 & 25.19 \\
\hline
\end{tabular}

${ }^{\text {a }}$ Theoretical residual $(\mathrm{TR} \%)=\left[(\right.$ weight of TIP $\left.) \times M_{\mathrm{TiO}_{2}} / M_{\mathrm{TIP}}\right] /\left[(\right.$ weight of PAA $)+($ weight of TIP $\left.) \times M_{\mathrm{TiO}_{2}} / M_{\mathrm{TIP}}\right]$; where $M_{\mathrm{TiO}_{2}}$ and $M_{\mathrm{TIP}}$ are the molecular weight of $\mathrm{TiO}_{2}$ and TIP, respectively.

$\mathrm{b}$ The residual weight was lower than theoretical residual weight. 


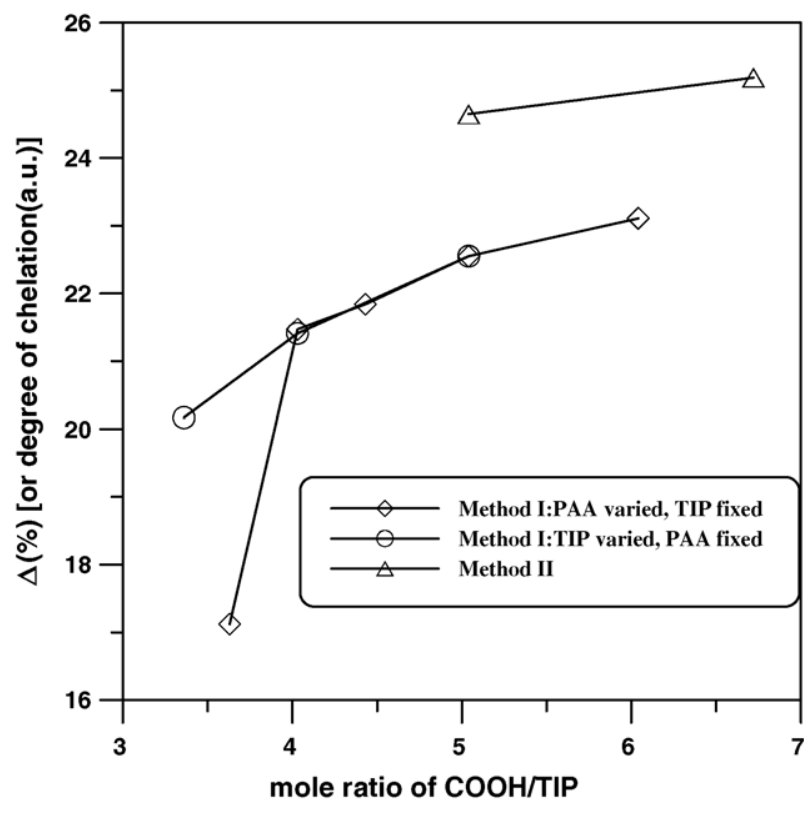

Fig. 11. The $\Delta$ value (or degree of chelation) vs. mole ratio of COOH/TIP.

roughly degree of chelation). The residual compounds at $800{ }^{\circ} \mathrm{C}$ were black, black and white and the $\Delta$ values were $24.65 \%, 25.35 \%$ and very low, respectively. Stronger degree of chelating represented a stronger interaction between PAA and titania, so the residual was black. Interestingly, in II-T1-P5-W2, the final state was white at $800{ }^{\circ} \mathrm{C}$. This white product was probably transformed by adding additional water to the solution, indicating that the reaction exhibited two effects. The first was the enhancement of the chelating capacity by the increase in the number of effective carboxylic acid groups because the PAA chains became more extension in the water solution. This effect inhibited the growth of titania. The second effect was the promotion of the hydrolysis and condensation of TIP by the added water, promoting the growth of titania. These two effects competed with each other. Clearly, the first effect was stronger in II-T1-P5-W1 but the second effect became very important in II-T1-P5-W2, when increasing the amount of water. Comparing the $\Delta$ values and the $T_{\mathrm{d}}$ values of II-T1-P5W0 and II-T(0.75)-P5-W0 in Table 3 indicated that the $\Delta$ value (or roughly degree of chelation) increased but $T_{\mathrm{d}}$ decreased as the amount of TIP decreased. The similar results were observed in hybrids of method I as described above. Fig. 11 shows the comparison of method I and method II for the $\Delta$ values (or roughly degree of chelation) of the hybrids with different ratios of PAA/TIP.

A comparison with I-T1-P5 clearly revealed that the interaction between PAA and titania in II-T1-P5-W0, synthesized by method II, was stronger than that in I-T1-P5, synthesized by method $\mathrm{I}$, as indicated by the $\Delta$ values (or roughly degree of chelation). In method I, the presence of water generated from partial esterification caused the fast hydrolysis and condensation reaction of TIP as TIP was added to the PAA solution. The TIP was not fully chelated with PAA in time. However, in method II, the carboxylic acid group chelated with TIP at a higher rate than esterification reaction. Thereafter, after the TIP had fully chelated with PAA, the hydrolysis and condensation of TIP occurred when the water molecules were released by the partial esterification of the carboxylic acid groups with butanol. This resulted in a stronger interaction between PAA and titania in the hybrid materials prepared from method II than that from method I, as shown in Fig. 11.

\subsection{DSC analysis}

The thermal behaviors of the hybrid materials and pure PAA were investigated by DSC and presented in Fig. 12. In Fig. 12, a few hybrids represented all of the hybrids, which according to DSC, exhibited the same behavior. Clearly, the glass transition temperature $\left(T_{\mathrm{g}}\right)$ of PAA, around $80{ }^{\circ} \mathrm{C}$, was eliminated because titania was incorporated, indicating that the thermal motion of PAA was confined by titania when the carboxylic acid groups of PAA chains were chelated with titania. This finding was consistent with the results obtained from FTIR and TGA.

\subsection{SEM analysis}

The size and shape of the hybrid aggregates and the degree of aggregation were obtained from SEM photographs. All of the sizes determined from the SEM photographs were aggregate sizes, not primary sizes. Fig. 13 shows the morphologies, obtained by FE-SEM of the prepared hybrids synthesized by methods I and II.

\subsubsection{Method I}

The sizes of I-T1-P7 and I-T1-P5 were in the range 60$80 \mathrm{~nm}$, as shown in Figs. 13(a) and (b), respectively. The result of similar sizes of I-T1-P7 and I-T1-P5 was probably due to the fact that titania grew relatively quickly because the water was present in the PAA solution in method I. The secondary

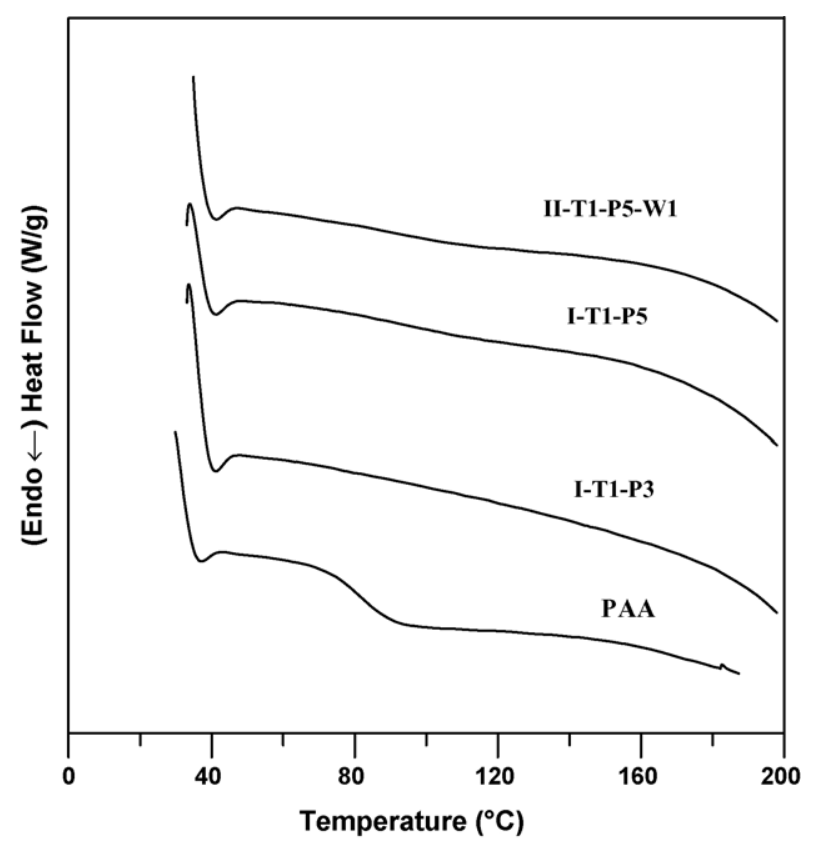

Fig. 12. DSC curves of the prepared hybrids and pure PAA. 

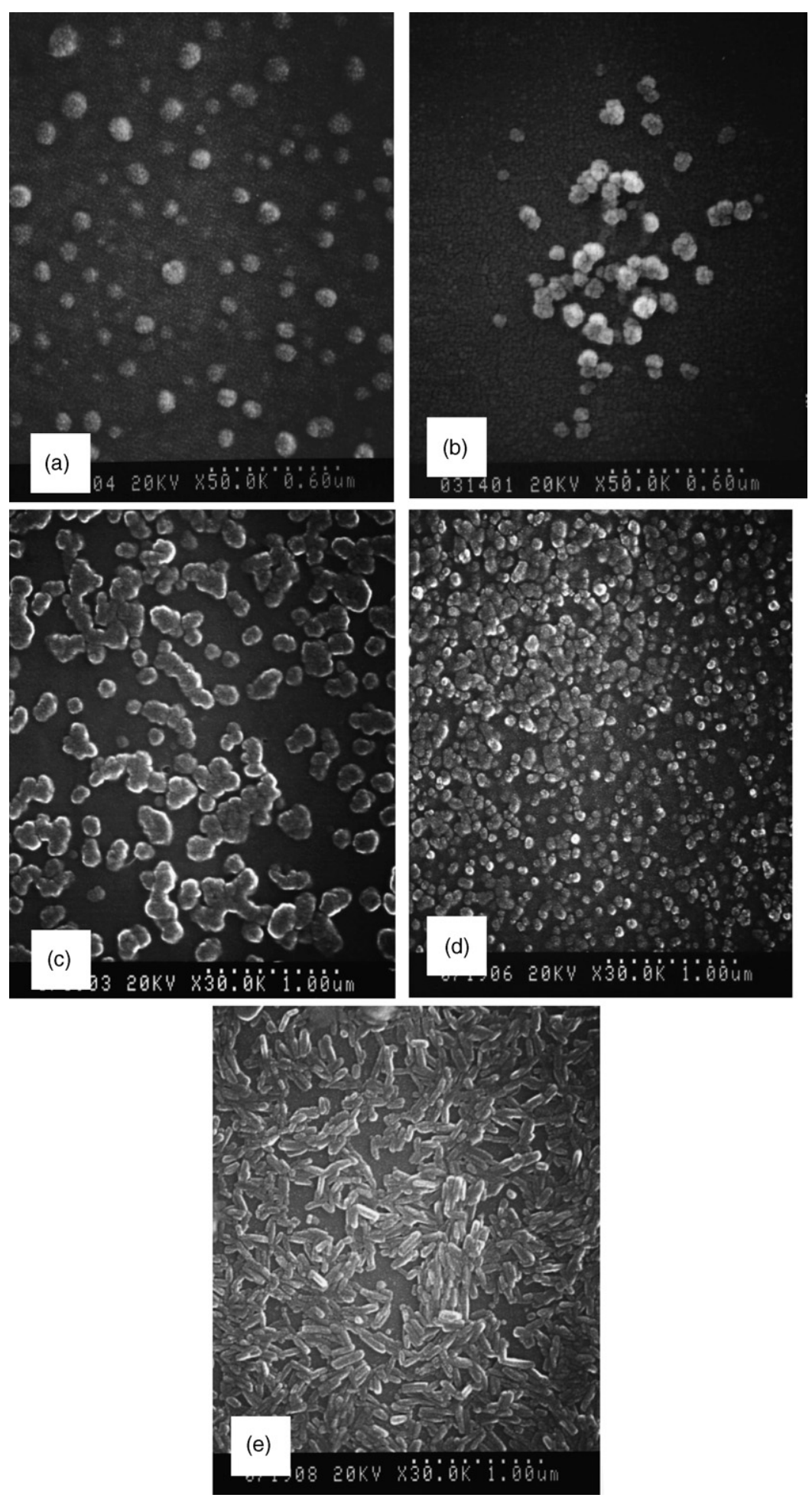

Fig. 13. SEM photographs of the prepared hybrid. (a) I-T1-P7, (b) I-T1-P5, (c) II-T1-P5-W0, (d) II-T(0.75)-P5-W0, and (e) II-T1-P5-W1.

aggregation of the hybrid aggregates was more obvious in I-T1P5. As mentioned in the phase diagram section, carboxylic acid chelated on the surface of the hybrid particles provided steric hindrance to prevent particles from aggregation. The presence of sufficient PAA chains, and, therefore, sufficient carboxylic acid groups, was suggested to reduce the degree of aggregation, as seen in I-T1-P7.

\subsubsection{Method II}

Fig. 13(c)-(e) display the morphologies of the hybrids prepared by method II. Comparing II-T1-P5-W0 and II$\mathrm{T}(0.75)-\mathrm{P} 5-\mathrm{W} 0$, the size of the hybrid aggregates and the degree of aggregation all decreased as the amount of TIP decreased, as presented in Fig. 13(c) and (d). In other words, the size and the aggregation of the hybrid decreased as the ratio of 
PAA/TIP increased. As in I-T1-P7 and I-T1-P5 in method I, sufficient PAA reduced the degree of aggregation. A smaller size in II-T(0.75)-P5-W0, in comparison with II-T1-P5-W0, was related to the inhibition of the hydrolysis of TIP chelated by the large number of carboxylic acid groups, which constrained the growth of titania. In method II, the TIP was more effectively bound to the PAA chains and the reaction of hydrolysis and condensation proceeded relatively slowly because water was released gradually from partially esterification. Hence, the ratio of PAA/TIP affected not only the aggregation but also the size of the hybrid aggregates significantly.

Notably, the hybrid aggregates, II-T1-P5-W1, became rodlike from spherical, when the sol-gel reaction was conducted with adding additional water, as shown in Fig. 13(e). Just as stated in TGA section, water changed the conformation of the PAA chains and slowed down the growth of titania. The PAA chains were extended when water was added to the PAA solution, causing the growth of titania to follow the conformation of the PAA chains.

It was worth to mention that the size of the hybrid aggregates of II-T1-P5-W0 was approximately $150 \mathrm{~nm}$, which exceeded that of I-T1-P5, whereas the degree of chelation was higher than that of I-T1-P5, as determined by TGA. The larger size of II-T1P5-W0 than I-T1-P5 was related to the gel formation in preparation as described in the phase diagram. II-T1-P5-W0 was in a gel state firstly after the PAA was added, followed by the growth of titania particles in the gels, then the segregation of the hybrid particles in the further steps of heating process and drying. Therefore, the larger size of hybrid aggregates was observed.

\section{Conclusion}

In this work, stable colloids of PAA-titania hybrid were prepared via in situ sol-gel reaction. Various mole ratios of PAA/TIP/water and synthetic routes were used. The phase diagram revealed that the environment of the sol-gel reaction controlled the phase of the hybrid. FTIR confirmed the formation of a chelating bond between the PAA chains and titania. The degree of chelation increased with increasing the ratio of PAA to TIP within our experimental range of ratios, as determined by TGA. Additionally, method II exhibited stronger chelation than method I. Incorporating titania enhanced the thermal properties and the constrained thermal motion of PAA, as determined by TGA and DSC. The SEM photographs indicated that the environments of hydrolysis and condensation, including whether the precursor was chelated and whether the solution contained water, strongly affected the degree of aggregation and the growth of titania.

\section{Acknowledgements}

The authors would like to thank the National Science Council of the Republic of China under Contract No. NSC. 912216-E-002-020 for financially supporting this research. The authors also thank Instrumentation Center, National Taiwan University, Ching-Yen Lin, and Chih-Yuan Tang for the using of SEM.

\section{Reference}

[1] C.Y. Kwong, A.B. Djurišic, P.C. Chui, K.W. Cheng, W.K. Chan, Influence of solvent on film morphology and device performance of poly(3-hexylthiophene): $\mathrm{TiO}_{2}$ nanocomposite solar cells, Chem. Phys. Lett. 384 (4-6) (2004) 372-375.

[2] S.E. Shaheen, C.J. Brabec, N.S. Sariciftci, F. Padinger, T. Fromherz, J.C. Hummelen, 2.5\% Efficient organic plastic solar cells, Appl. Phys. Lett. 78 (6) (2001) 841-843.

[3] T.J. Trentler, T.E. Denler, J.F. Bertone, A. Agrawal, V.L. Colvin, Synthesis of $\mathrm{TiO}_{2}$ nanocrystals by nonhydrolytic solution-based reactions, J. Am. Chem. Soc. 121 (7) (1999) 1613-1614.

[4] F. Hide, B.J. Schwartz, M.A. Díaz-García, A.J. Heeger, Laser emission from solutions and films containing semiconducting polymer and titanium dioxide nanocrystals, Chem. Phys. Lett. 256 (4-5) (1996) 424-430.

[5] K.V.P.M. Shafi, A. Ulman, X. Yan, N.L. Yang, M. Himmelhaus, M. Grunze, Sonochemical preparation of silane-coated titania particles, Langmuir 17 (5) (2001) 1726-1730.

[6] T. Murakata, R. Yamamoto, Y. Yoshida, M. Hinohara, T. Ogata, S. Sato, Preparation of ultra fine $\mathrm{TiO}_{2}$ particles dispersible in organic solvents and their photocatalytic properties, J. Chem. Eng. Jpn. 31 (1) (1998) 21-28.

[7] L. Crouzet, D. Leclercq, P.H. Mutin, A. Vioux, Organosilsesquioxanetitanium oxide hybrids by nonhydrolytic sol-gel processes. Study of the rearrangement of Si-O-Ti bonds, Chem. Mater. 15 (7) (2003) 1530-1534.

[8] W.J.E. Beek, R.A.J. Janssen, Photoinduced electron transfer in heterosupramolecular assemblies of $\mathrm{TiO}_{2}$ nanoparticles and terthiophene carboxylic acid in apolar solvents, Adv. Funct. Mater. 12 (8) (2002) 519-525.

[9] X. Zhang, S. Du, Y. Chen, L. Zhang, Y. Cao, X. Chai, Y. Bai, L. Xiao, T. Li, Preparation of covalently modified organic-inorganic composite nanoparticles and their interfacial electron transfer researches, Thin Solid Films 327-329 (1998) 563-567.

[10] H. Ding, M.K. Ram, C. Nicolini, Construction of organic-inorganic hybrid ultrathin films self-assembled from poly(thiophene-3-acetic acid) and $\mathrm{TiO}_{2}$, J. Mater. Chem. 12 (12) (2002) 3585-3590.

[11] E.J. Nassar, R.R. Goncalves, M. Ferrari, Y. Messaddeq, S.J.L. Ribeiro, Titania-based organic-inorganic hybrid planar waveguides, J. Alloys Compd. 344 (1-2) (2002) 221-225.

[12] W. Que, Y. Zhou, Y.L. Lam, Y.C. Chan, C.H. Kam, Optical and microstructural properties of sol-gel derived titania/organically modified silane thin films, Thin Solid Films 358 (1-2) (2000) 16-21.

[13] C.C. Chang, W.C. Chen, High-refractive-index thin films prepared from aminoalkoxysilane-capped pyromellitic dianhydride-titania hybrid materials, J. Polym. Sci. Part A: Polym. Chem. 39 (19) (2001) 3419-3427.

[14] P. Innocenzi, G. Brusatin, M. Guglielmi, R. Signorini, R. Bozio, M. Maggini, 3-(Glycidoxypropyl)-trimethoxysilane- $\mathrm{TiO}_{2}$ hybrid organicinorganic materials for optical limiting, J. Non-Cryst. Solids 265 (1-2) (2000) 68-74.

[15] Z.H. Huang, K.Y. Qiu, Y. Wei, Properties of hybrid materials incorporating tetrabutyl titanate and tetraethoxysilane with ethylene-propylene nonconjugated diene terpolymer (EPDM-ENB) via sol-gel process, J. Polym. Sci. Part A: Polym. Chem. 35 (12) (1997) 2403-2409.

[16] R. Helmy, A.Y. Fadeev, Self-assembled monolayers supported on $\mathrm{TiO}_{2}$ : Comparison of $\mathrm{C}_{18} \mathrm{H}_{37} \mathrm{SiX}_{3}\left(\mathrm{X}=\mathrm{H}, \mathrm{Cl}, \mathrm{OCH}_{3}\right), \mathrm{C}_{18} \mathrm{H}_{37} \mathrm{Si}\left(\mathrm{CH}_{3}\right)_{2} \mathrm{Cl}$, and $\mathrm{C}_{18} \mathrm{H}_{37} \mathrm{PO}(\mathrm{OH})_{2}$, Langmuir 18 (23) (2002) 8924-8928.

[17] P.A. van Hal, M.M. Wienk, J.M. Kroon, W.J.H. Verhees, L.H. Slooff, W.J.H. van Gennip, P. Jonkheijm, R.A.J. Janssen, Photoinduced electron transfer and photovoltaic response of a MDMO-PPV:TiO ${ }_{2}$ bulk-heterojunction, Adv. Mater. 15 (2) (2003) 118-121.

[18] S. Roux, G.J.A.A. Soler-Illia, S. Demoustier-Champagne, P. Audebert, C. Sanchez, Titania/polypyrrole hybrid nanocomposites built from in-situ generated organically functionalized nanoanatase building blocks, Adv. Mater. 15 (3) (2003) 217-221.

[19] D.C. Schnitzler, M.S. Meruvia, I.A. Hümmelgen, A.J.G. Zarbin, Preparation and characterization of novel hybrid materials formed from $(\mathrm{Ti}, \mathrm{Sn}) \mathrm{O}_{2}$ nanoparticles and polyaniline, Chem. Mater. 15 (24) (2003) 4658-4665.

[20] Y. Tong, Y. Li, F. Xie, M. Ding, Short communication preparation and characteristics of polyimide- $\mathrm{TiO}_{2}$ nanocomposite film, Polym. Int. 49 (11) (2000) 1543-1547. 
[21] P.C. Chiang, W.T. Whang, The synthesis and morphology characteristic study of BAO-ODPA polyimide/TiO 2 nano hybrid films, Polymer 44 (8) (2003) 2249-2254.

[22] R.A. Caruso, M. Antonietti, M. Giersig, H.P. Hentze, J. Jia, Modification of $\mathrm{TiO}_{2}$ network structures using a polymer gel coating technique, Chem. Mater. 13 (3) (2001) 1114-1123.

[23] Ö. Dag, I. Soten, Ö. Celik, S. Polarz, N. Coombs, G.A. Ozin, Solventless acid-free synthesis of mesostructured titania: nanovessels for metal complexes and metal nanoclusters, Adv. Funct. Mater. 13 (1) (2003) 30-36.

[24] R.A. Caruso, J.H. Schattka, Cellulose acetate templates for porous inorganic network fabrication, Adv. Mater. 12 (24) (2000) 1921-1923.

[25] B.M. Novak, Hybrid nanocomposite materials - between inorganic glasses and organic polymers, Adv. Mater. 5 (6) (1993) 422-433.

[26] S. Doeuff, M. Henry, C. Sanchez, J. Livage, Hydrolysis of titanium alkoxides: modification of the molecular precursor by acetic acid, J. Non-Cryst. Solids 89 (1-3) (1987) 206-216.

[27] J. Zhang, S.C. Luo, L. Gui, Poly(methyl methacrylate)-titania hybrid materials by sol-gel processing, J. Mater. Sci. 32 (5-6) (1997) 1469-1472.

[28] F.X. Perrin, V. Nguyen, J.L. Vernet, Mechanical properties of polyacrylictitania hybrids - microhardness studies, Polymer 43 (23) (2002) 6159-6167.
[29] P.L. Kuo, T.C. Chang, L.M. Lu, Functional polymers for colloidal applications. I. Structural effects of lipophile-modified polyacrylates on adsorption and dispersion ability, J. Appl. Polym. Sci. 44 (5) (1992) 859867.

[30] D.A. Siuzdak, P.R. Start, K.A. Mauritz, Surlyn ${ }^{\circledR} /$ titanate hybrid materials via polymer in situ sol-gel chemistry, J. Polym. Sci. Part B: Polym. Phys. 41 (1) (2003) 11-22.

[31] K.F. Silveira, I.V.P. Yoshida, S.P. Nunes, Phase separation in PMMA/silica sol-gel systems, Polymer 36 (7) (1995) 1425-1434.

[32] J. Dong, Y. Ozaki, K. Nakashima, Infrared, Raman, and Near-Infrared spectroscopic evidence for the coexistence of various hydrogen-bond forms in poly(acrylic acid), Macromolecules 30 (4) (1997) 11111117.

[33] H.R. Motzer, P.C. Painter, M.M. Coleman, Interactions in miscible blends of poly(styrene-co-methacrylic acid) with copolymers containing vinylpyrrolidone and vinylpyridine groups, Macromolecules 34 (23) (2001) 8390-8393.

[34] S.W. Kuo, F.C. Chang, Miscibility and hydrogen bonding in blends of poly(vinylphenol-co-methyl methacrylate) with poly(ethylene oxide), Macromolecules 34 (12) (2001) 4089-4097. 